\title{
A Cross Sectional Descriptive Study on Non Descent Vaginal Hysterectomy (NDVH)
}

\author{
Shahana Begum ${ }^{1 *}$ \\ Rowshan Akhtar \\ Sharmilla Barua' \\ Jannatul Ferdous ${ }^{2}$
}

'Department of Obstetrics and Gynaecology Chittagong Medical College

Chittagong, Bangladesh.

${ }^{2}$ Department of Obstetrics and Gynaecology Upzilla Health Complex, Laxmichari

Khagrachari, Bangladesh.
*Correspondence to:

\section{Dr. Shahana Begum}

Junior Consultant

Department of Obstetrics and Gynaecology

Chittagong Medical College

Chittagong, Bangladesh

Mobile: +8801714288794

Email: drshahanashelly@yahoo.com

\begin{abstract}
Aims and objectives: The objective of this study was to determine the less post operative morbidities and better compliance of the patient following vaginal hysterectomy in case of non descent uterus. Materials and Methods: This is a cross sectional descriptive study of patients admitted in Chittagong medical college Hospital and different private clinics between May 2010 and April 2013. Total 126 patients requiring hysterectomy recruited for the study. Indications of Non-descent vaginal hysterectomy (NDVH) were dysfunctional uterine bleeding ( DUB), fibroid uterus, adenomyosis, chronic cervicitis, CIN- II and III, endomertrial hyperplasia, PID and invasive mole. NDVH were performed in cases with mobile uterus, size not exceding 14 weeks of gestation, and with adequate vaginal access. Morcellation techniques like bisection, myomectomy, wedge debulking or combinatoin of these were employed in bigger and firmer uteri. Results: Age ranged from 35 -60 years with majority $(68.25 \%)$ between 45 and 50 years and $8.70 \%$ above 50 years. Seventy nine $(62.698 \%)$ women were of 3 or more parity, 38 cases $(30.15 \%)$ had two and 9 cases $(7.14 \%)$ had one. Preoperative uterine size varied from eight weeks size 98 (77.77\%), 12 weeks size 21 cases (16.66\%) and more than 12 weeks size 7 cases (5.55\%). Table 1 depicts the indications for NDVH. One hundred nineteen patients had hysterectomy and remaining 7 had hysterectomy with salpingo-oophorectomy. Eighty four $(66.66 \%)$ operations were complete within 90 minutes and remainder needed 90 minutes to 3 hours. Average blood loss was up to $200 \mathrm{ml}$ in 91 (72.20\%) cases and in other cases it was more than $200 \mathrm{ml}$. Average hospital stay was 2 days in the majority $(76.20 \%$ ) while 3-5 days in others. Bladder injury occurred in 6 cases $(4.76 \%)$ and rectum injury in 1 case $(0.79 \%)$ during operation. Postoperatively 12 $(9.52 \%)$ patient were suffering from secondary haemorrhage and 15 (11.11\%) patient from vault granuloma. Analgesic requirement was at minimum during post operative period. Cost was reduced with the compared to the other route of hysterectomy. Conclusion: NDVH is a less invasive technique with benefits, which includes shorter hospital stay and faster convalescence and avoid abdominal wound complications. It should be a primary methods for removal of large uterus provided one is familiar with morcellation technique.
\end{abstract}

Key words: Non descent vaginal hysterectomy; abdominal hysterectomy; morcellation.

\section{INTRODUCTION}

Hysterectomy is the most common major gynecological surgical procedure. It can be done by abdominal or vaginal route and with the help of laparoscopy ${ }^{1}$. Laparoscopic assisted vaginal hysterectomy (LAVH) and total laparoscopic hysterectomy (TLH) although gaining more popularity now a days, though it is associated with higher cost, longer duration of operation, and need general anaesthesia ${ }^{2}$. On the other hand vaginal hysterectomy is associated with reduced morbidity and lower health care cost compared to laparoscopic technique ${ }^{3}$. It is exclusively done under spinal anaesthesia and also preferred in high risk cases like obesity and it is also a cosmetic surgery (scarless operation) $)^{4}$. 
Hysterectomy is commonly indicated for uterine leiomyoma, dusfunctional uterine bleeding, adenomyosis, eddometriosis, utero vaginal prolapse, premalignant and malignant condition ${ }^{5}$. From many large scale surveys of hysterectomies practice have shown that $70-80 \%$ of hysterectomies are performed by the abdominal approach ${ }^{6}$. In the management of uterovaginal prolapsed, the vaginal route is normally used but this indication accounts for only approximately $10 \%$ of the cases ${ }^{7}$. With the recent advances and innovation of surgery led to surgeon in learning vaginal hysterectomy irrespective of non-descent uterus. One of the most dramatic changes in the route of removal of uterus during the past few years is switching over from abdominal to vaginal route ${ }^{8}$. Today gynecologists are becoming vaginal surgeons. They have started to believe that every uterus can be and should be removed vaginally unless the route is contraindicated ${ }^{9}$. Vaginal hysterectomy in larger sized uterus is facilitated by bisection, myomectomy, debulking, coring and clampless approach ${ }^{10}$. Vaginal hysterectomy has been found to be associated with less febrile morbidity, less bleeding necessitating transfusion, shorter hospitalization and faster convalescence than abdominal hysterectomy ${ }^{11}$. There is evidence for lower morbidity and a quick recovery in patients undergoing vaginal compared with abdominal hysterectomy. Now the question is arises why relatively few hysterectomies are performed vaginally still today, because Training and experience in vaginal surgery appear to be the major determinants of the type of hysterectomy performed. The aim of this study is to determine the short-term morbidity for vaginal hysterectomy done for non-descent uterus. Another aim of this present study is to report the personal experience in performing non descent vaginal hysterectomy (NDVH) for benign gynaecological indications and to explore different surgical techniques that make vaginal hysterectomy simplier and easier to perform.

\section{MATERIALS \& METHODS}

This is a cross sectional descriptive study carried out in Chittagong Medical College Hospital and different private clinics of Chittagong from May 2010 to April 2013. One hundred and twenty six women scheduled for hysterectomy for benign conditions of uterus were included. Data analysis was carried out by mean median percntage and relative risk of NDVH with $95 \%$ confidence intervals $(\mathrm{p}<0.05)$.

\section{Inclusion criteria}

Fibroid uterus, DUB, adenomyosis, endometrial hyperplasia, CIN-II and III, chronic cervicitis, PID, postmenopausal bleeding and invasive mole with previous history of one caesarean section, without any descent of uterus.

Exclusion criteria:

Malignant condition of uterus and cervix, benign condition of the pelvic organ with previous history of two or more caesarean section and suspected dense adhesion and utero vaginal prolapsed.

A preformed questionnaire was made for data collection. Detailed history and thorough clinical examination was done in each case. A written informed consent was taken from each patient. Particular attention was given to operative time, per and post-operative complications, amount of blood loss and hospital stay.
All cases were re-assesed in operation theatre after patient was anaesthetized to see the size, mobility of the uterus, vaginal accessibility and laxity of the pelvic muscles. All the principles of vaginal hysterectomy in non-descent uterus were followed and appropriate instruments were also used ${ }^{12-13}$.

All cases were done under spinal anaesthesia. Extended lithotomy position with legs apart provided good spaces for assistants to stand and assist without discomfort. Labial stitches made the surgical field wide for better visualization. Urinary bladder was emptied to find out the vesicouterine space clearly. The mobility of the uterus and surrounding structures was cheked by holding the cervix with volsellum forceps moving the uterus in all directions. The steps of operation are depicted in figures 1 to 6 .

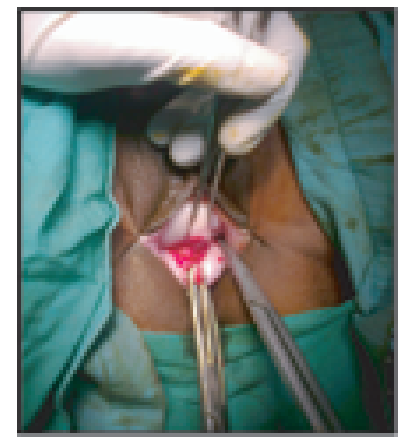

Figure 1: To cut the vesicocervical ligament

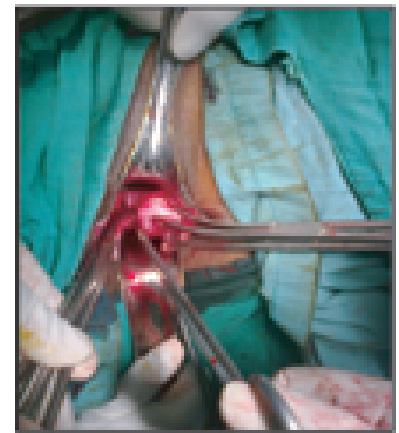

Figure 3: $1^{\text {th }}$ Clamp of

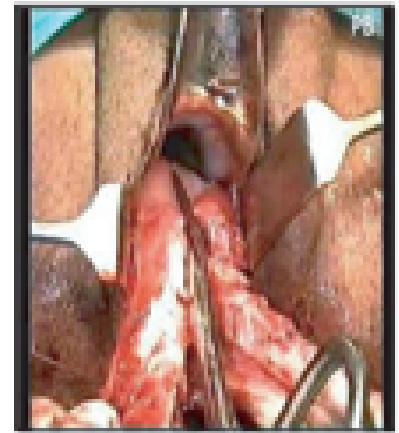

Figure 5: Bisection of uterus operation

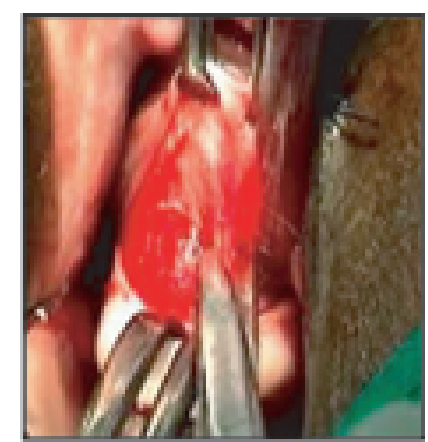

Figure 2: To open the pouch of douglas

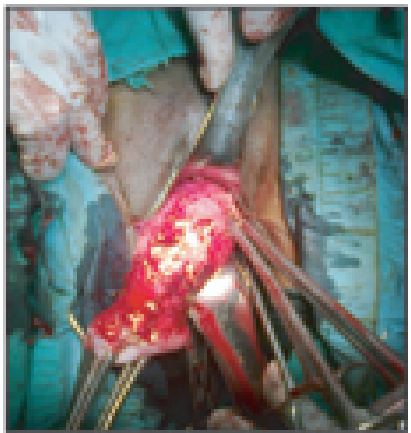

Figure 4: Third clamp of hysterectomy

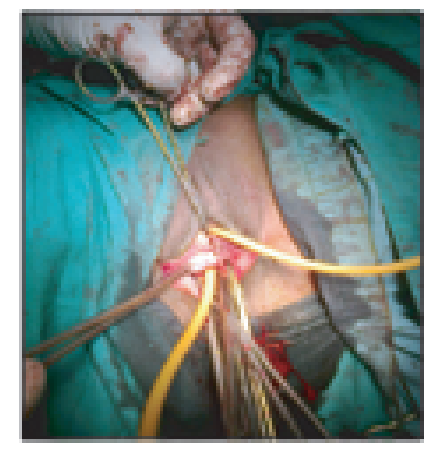

Figure 6: Drain and catheter
Checked for haemostasis, then cleaned and packed with gauge. The pack and catheter were removed after 24 hours. 


\section{RESULTS}

Age ranged from 35 -60 years with majority (68.25\%) between 45 and 50 years and $8.70 \%$ above 50 years. Seventy nine (62.698\%) women were of 3 or more parity, 38 cases $(30.15 \%)$ had two and 9 cases $(7.14 \%)$ had one. Preoperative uterine size varied from eight weeks size $98(77.77 \%), 12$ weeks size 21 cases $(16.66 \%)$ and more than 12 weeks size 7 cases $(5.55 \%)$. Table 1 depicts the indications for NDVH. One hundred nineteen patients had hysterectomy and remaining 7 had hysterectomy with salpingo-oophorectomy. Eighty four $(66.66 \%)$ operations were complete within 90 minutes and remainder needed 90 minutes to 3 hours. Average blood loss was up to $200 \mathrm{ml}$ in $91(72.20 \%)$ cases and in other cases it was more than $200 \mathrm{ml}$. Average hospital stay was 2 days in the majority (76.20\%) while 3-5 days in others. Table 2 depicts the peroperative and postoperative copmplications. Analgesic requirement was at minimum during post operative period. Cost was reduced in comprarison to the other route of hysterectomy.

Table 1: Indications for performing NDVH

$\begin{array}{llc}\text { Indication }(\mathrm{n}=126) & & \text { Percentage }(\%) \\ \text { Dysfunction uterine bleeding } & 42 & 33.33 \\ \text { Fibroid } & 29 & 23.33 \\ \text { Adenomyosis } & 14 & 11.11 \\ \text { Cervical intraepithelial neoplasia II and III } & 16 & 12.69 \\ \text { Endometrial hyperplasia } & 8 & 6.34 \\ \text { Chronic cervicitis } & 5 & 3.94 \\ \text { Postmenopausal bleeding } & 7 & 5.55 \\ \text { Pelvic inflammatory diseases } & 4 & 3.17 \\ \text { Invasive mole } & 1 & 0.79\end{array}$

Table 2: Surgical complications

\begin{tabular}{lcc} 
Complications & No of the patient & Percentage \\
Intraoperative & & \\
Bladder injury & 6 & 4.76 \\
Rectum injury & 1 & 0.79 \\
Post operative & & \\
Secondary haemarrhage & 12 & 9.52 \\
Vault granuloma & 15 & 11.11 \\
Total & 34 & 26.28 \\
\hline
\end{tabular}

\section{DISCUSSION}

The favorable characteristic for vaginal surgery was the laxity of vaginal wall which facilitates vaginal repair large uterus up to the size of 12 weeks gestation and usually without need for oophorectomy ${ }^{13}$. However, oophorectomy could easily be done after performing hysterectomy through the vaginal route ${ }^{14}$. In our study commonest indication for NDVH was DUB failure of or noncompliance to the medical treatment followed by fibroid uterus. NDVH is a good option for fibroid uterus provided the surgeon is familiar with morcellation technique. ${ }^{14}$ Bisection of uterus was done in adenomyosis cases and we also did myomectomy in larger uterus of upto 16 weeks size with multiple fibroids. However, Dorsey JW et al recommended laparoscopic assisted vaginal hysterectomy (LAVH) for uterus of more than 12 weeks size.
The indications for hysterectomy in this study are more or less similar with the indications for non-descent vaginal hysterectomy reported by others ${ }^{15}$. In our study the contraindications are previous history of two caesarean section, severe degree of endometriosis, nulliparous women because vaginal approach was not possible though four cases with pelvic inflammatory diseases was selected for NDVH and successfully done without any difficulties. In case of postmenopausal women proper evaluation was done very carefully, every case was evaluated with diagnostic D\&C to exclude malignancy. In case of endometrial carcinoma preferred surgery is radical hysterectomy rather than $\mathrm{NDVH}^{16}$. Though in this route bilateral salpingoophorectomy easily possible after doing NDVH but lymph node clearance is not possible ${ }^{16}$.

Adam Magos et al selected woman with fibroid uterus between 14-20 weeks of gestational size for bisection, myomectomy, morcellation and coring to reduce the uterine size ${ }^{17}$. Uterine morecellation is the key to a successful operation in case of vaginal surgery and obviates the need for abdominal or laparoscopically assisted hysterectomy for large and firm uteri. Thirty three of our 126 cases needed morcellation. A large number of our patients were between 40 and 45 years of age and they could be easily convinced about vaginal route of operation as they could return to house hold activities earlier.

In few cases salpingo-oophorectomy was also done in our series. It was critical to evaluate preoperatively to exclude ovarian malignancy which could be a contraindication for oophorectomy through vaginal route. Blood loss was little in most of the cases in our series and only 1-2 bag of blood was transfused during operation and post operative period in some cases. Operative complications were in small number of cases. Bladder injury occurred during separation of vesicocervical ligaments and rectum injury during opening of the pouch of Douglas.

It is now accepted that LAVH is preferred to abdominal hysterectomy, but involves general anaesthesia, duration of operation and cost are was more. Adequate knowledge and skill of surgeon is required in both type of surgery either laparosecopic surgery or NDVH. However, for non-descent uterus if vaginal route is feasible, NDVH is preferred to LAVH.

The requirement of post operative analgesic was less in NDVH in our series and is comparable to other studies ${ }^{18}$. The hospital stay in our series was 2 days in majority instances. The length of hospital stay reported by Dorsey JW et al was 3.5 and 4.4 days for total vaginal hysterectomy and total abdominal hysterectomy respectively ${ }^{15}$. The cost of the operation was significantly lower for vaginal hysterectomy. Reduction in postoperative analgesic requirement and shorter hospital stay are the factors responsible. An analysis for cost between abdominal, LAVH and vaginal hysterectomy by Raansom SB revealed that vaginal hysterectomy was significantly more cost effective. Our cases incurred reduced cost for use decreased number of suture materials in addition to mentioned factors. With experience, operative time, blood loss and complications can be reduced considerably. Thus this scarless approach should be chosen as a method of hysterectomy ${ }^{19}$.

\section{CONCLUSION}

Vaginal hysterectomy is a less invasive technique with benefits of shorter hospital stay and faster convalescence. It is the surgical method of choice for benign conditions of uterus. Vaginal hysterectomy should be a primary method for removal of uterus, if not contraindicated.

\section{DISCLOSURE}

All the authors declared no competing interest. 


\section{REFERENCES}

1. Farhana Dewan, Laila Arjuman Banu,Anwara Begum.Vaginal hysterectomy in non descent uterus; Bangladesh journal of obstetrics and gynaecology; 2003; 1(1).

2. Banasree Bhadra, Arun Paul Chawdhury,Amit Tolasaria, Nandi nupur. Non Descent vaginal hysterectomy : Personal experiences in 158 cases:Al Ameen J Med sci ; 2011; 4(1) 23-27.

3. Kumar S , Antony ZK. Vaginal hysterectomy for benign nonprolapsed uterus- initial experiences. J Obstet Gynecol Ind.2004;54:60-3.

4. Unger JB. Vaginal hysterectomy for the women with moderately enlarged uterus weinging 200-700 grams. Am J Obstet Gynecol 1999;180: 1337-44.

5. Kovac SR, Cruikshank SH. Guidelines to determine the route of oophorectomy with hysterectomy . Am J Obstet gynecol .1996;1483-88.

6. Dorsey JH, Steinberg EP, Holtz PM, Clinical indication for hysterectomy route: Patient characteristics or physician preferences. Am J Obstet Gynecol .1995;173 (5): 1452-60.

7. Sheth S S. The scope of vaginal hysterectomy. Eur J Obstet Gynecol Repord Biol 2004; 115: 224-30.

8. Davies A, Wizza E, Bournas N. How to increases the proportion of hysterectomy performed vaginally. Am J obstes Gynecol.1998;179:1008-12.

9. Meikle SF, Nugent SW,Oleans M. complication and recovery of laparoscopy assisted vaginal hysterectomy compared with abdominal and vaginal hysterectomy. Obstet Gynecol.1997;89:304-11.

10. Mazdisnian F, Kurzel RB, Coe S. Vaginal hysterectomy by uterine morcellation:efficient, nonmorbid procedure. Obstet gynecol.1995;86:60-4.

11. Wilcox LS, Koonin LM, Prokas R,Strauss LT, Xia Z,Peterson HB. Hysterctomy in the united states, Am J Obstet Gynecol.1998-1990; 83:545-55.

12. Vessey MP, Villard -Mackintosh I,Mcperson K, Coulter A, Yeates D. Epidemiology of hysterectomy; Findings in a large cohort study. Br J Obstet gynecol 1992;99:402-7.

13. Nezhat F, Nezhat C, Gorden S, Williams E. Laparoscopic versus abdominal hysterectomy. J Perod Med. 1992;37:247-50.

14. Ottosen C, Lingman G, Ottosen L, Three method of hysterectomy; a randomized, prospectomy syudy of short term outcome.Br J Obstet Gynecol . 2000; 107: 1380-85.

15. Dancoisne P, Abossolo T, Orvian E, Tauaillion J, Sommer JC, Rivicree JP, Amat D. Criteria for choice of vaginal hysterectomy for lesion other than invasive cancer. Rev-Fr-Gynaecol-Obstet.1994;89(1):11-14.

16. Magos A, Bournas N, Sinha R, Richardson RF. Vaginal hysterectomy for large uterus. Br J Obstet Gynecol. 1996;103:246-51.

17. Hoffman MS, DeCesare S and Kalter C. Abdominal hysterectomy versus transvaginal morcellation for removal of enlarged uterus. Am J Obstet Gynecol, 1996; 88(4):560-64.

18. Dock DK, Mao J. Vaginal hysterectomy with and without morcellation: The university of new Mexico hospital experiences, Obstet Gynecol, 1996; 88(4) 560-63.

19. Sheith SS. The place of oophorectomy with hysterectomy. Br. J obstet Gynecol,1991;98:662-666 